\title{
Foot and Mouth Disease atmospheric dispersion system
}

\author{
Keith Lambkin ${ }^{1}$, James Hamilton ${ }^{1, *}$, Guy McGrath ${ }^{2}$, Paul Dando ${ }^{3}$, and Roland Draxler, ${ }^{4},{ }^{*}$ \\ ${ }^{1}$ Met Éireann - The Irish Meteorological Service, Dublin, Ireland \\ ${ }^{2}$ CVERA - Centre for Veterinary Epidemiology and Risk Analysis, School of Veterinary Medicine, \\ University College Dublin, Dublin, Ireland \\ ${ }^{3}$ ECMWF - European Centre for Medium-Range Weather Forecasts, Reading, UK \\ ${ }^{4}$ NOAA/Air Resources Laboratory, College Park, Maryland, USA \\ *retired
}

Correspondence: Keith Lambkin (keith.lambkin@met.ie)

Received: 11 January 2019 - Accepted: 15 May 2019 - Published: 27 June 2019

\begin{abstract}
A decision support system to aid in the risk evaluation of airborne animal diseases was developed for Ireland. The system's primary objective is to assist in risk evaluation of the airborne spread of Foot and Mouth Disease (FMD). The operational system was developed by Met Éireann - the Irish Meteorological Service and CVERA (Centre for Veterinary Epidemiology and Risk Analysis), in co-operation with NOAA-ARL (National Oceanic and Atmospheric Administration - Air Resources Laboratory) and ECMWF (European Centre for Medium-Range Weather Forecasts). The infrastructure largely relies on the HYSPLIT dispersion model driven by both ECMWF meteorological forecasts for longer range simulations, and HARMONIE-AROME meteorological forecasts, a high resolution local area meteorological model, ideal for shorter range national emissions. Following on from previous work by the Bureau of Meteorology, Australia as well as the Australian Department of Agriculture, Fisheries and Forestry, further modifications were made to the HYSPLIT source code to improve the model's characterisation of the Foot and Mouth Disease virus. FMD is a highly infectious disease among cloven hoofed animals that can transmit via airborne means. Biological characteristics related to temperature, humidity, lifespan as well as atmospheric washout were all incorporated either through new or existing functionality of the dispersion model. Combining the model dispersion capabilities of HYSPLIT with a virus emission model and GIS mapping software with farmland zoning, the disease dispersion system becomes a powerful analysis and decision support tool. This airborne animal disease atmospheric dispersion system helps improve emergency preparedness, as well as aid confinement and eradication strategies for relevant Irish authorities, during a disease outbreak.
\end{abstract}

\section{Introduction}

Foot and Mouth Disease (FMD) is a highly contagious virus of cloven-hoofed animals. It is primarily spread through animal to animal contact as well as through third party contact such as physical contact with contaminated farm equipment or feed, but it can also be spread through wind dispersion. Through loss of animal productivity, animal mortality and restrictions to international trade, an FMD outbreak has the potential to inflict enormous economic losses (Knight-Jones and Rushton, 2013).
The World Organisation for Animal Health (OIE) recognises countries to be in one of three FMD disease states: FMD present with/without vaccination, FMD-free with vaccination, and FMD-free without vaccination (World Organisation for Animal Health, 2019). Ireland, a leading beef and dairy supplier in Europe, maintains a FMD-free without vaccination status. This provides Ireland with the highest level of access to export markets. It is essential that Ireland retains this status as livestock are the most economically important component of Irish agriculture (Central Statistics Office, 2019). In order to preserve this FMD-free status, control strategies have been developed to assist in the control and 


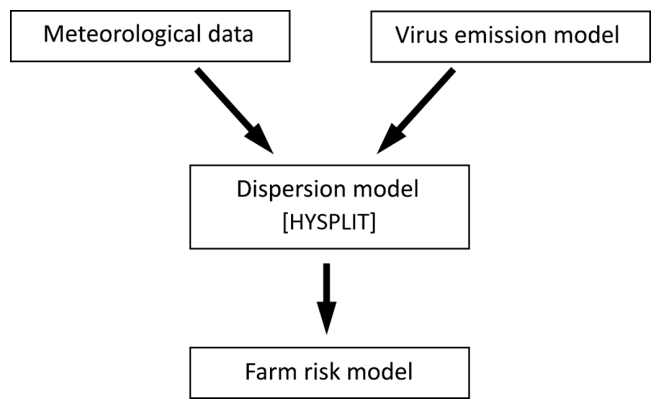

Figure 1. The four primary components of the Foot and Mouth Disease dispersion system. At its core is the NOAA-ARL HYSPLIT model which had minor additions made to it so it could better model the bio-meteorological characteristics of the FMD virus.

timely eradication in the event of an outbreak. Measures include animal movement restrictions, temporary vaccination of animals, and culling. While animal movement restrictions, can significantly help in reducing the risk of the virus spreading by animal to animal contact, it does not prevent the risk of airborne dispersion of the virus. The best defence against this is the rapid identification and culling of infected animals. In order to provide better support for the airborne threat, an operational FMD dispersion resource has been developed. This resource primarily has four parts as outlined in Fig. 1; (a) an atmospheric dispersion model, which requires (b) meteorological data and (c) a virus emission model, in order to produce dispersion plumes to feed into (d) a GIS farm exposure risk model.

\section{Method}

The Foot and Mouth Disease atmospheric dispersion system uses NOAA's HYSPLIT model at its core. HYSPLIT or Hybrid Single Particle Lagrangian Integrated Trajectory Model (Stein et al., 2015) is a complete system for computing simple air parcel trajectories to complex dispersion and deposition simulations. The HYSPLIT dispersion model has been extensively validated globally, is free to use and is supported by an active community of developers and users.

\subsection{Atmospheric dispersion model}

The survival of the FMD virus outside the host depends on a number of parameters. At the time of its initial development, the HYSPLIT model was not fully capable of modelling the FMD virus. Building on previous work from Bureau of Meteorology, Australia and the Australian Department of Agriculture, Fisheries and Forestry (Garner et al., 2006), HYSPLIT's source code was modified to include the bio-meteorological characteristics of the virus.

The survival of the virus depends on ambient temperature. While some simulations (Sørensen et al., 2001) use an on/off temperature switch to control the life of the virus, here the broader approach of Garner et al. (2006) was adopted. The HYSPLIT source code was modified so that the full population of virus 'particles' in an air temperature of $24^{\circ} \mathrm{C}$ and below are left unaffected and free to disperse. But for higher temperatures where the virus tends to die off, the concentration mass of virus particles decreases linearly between 24 and $30^{\circ} \mathrm{C}$ so that none remain by the time they reach $30^{\circ} \mathrm{C}$. This threshold of $24^{\circ} \mathrm{C}$ can be user defined (preserving the $6^{\circ} \mathrm{C}$ linear fall off) or the temperature dependence can be turned off altogether if desired. Temperature is typically not a limiting factor in Ireland as exceedances of $24^{\circ} \mathrm{C}$ are infrequent.

The survival of the virus also depends on humidity. The virus needs higher humidity to survive. Virus concentrations with relative humidity higher than $60 \%$ are left unaffected. The HYSPLIT code was again modified so that virus concentrations decrease exponentially as the humidity falls from $60 \%$ to $1 \%$ in line with Garner et al. This threshold of $60 \%$ can be user defined to describe different virus strains or the humidity dependence can be turned off altogether if desired.

Various publications use a virus decay constant to simulate particle ageing. For the foot and mouth disease virus, estimates of an effective half-life range from $30 \mathrm{~min}$ (Garner et al., 2006) to $2 \mathrm{~h}$ (Sørensen et al., 2001). This constant is also dependent on the strain of the virus. To be conservative the virus decay constant has been defined to be $2 \mathrm{~h}$ by default but this can be easily redefined by the user to suit their needs. Particle ageing can of course be turned off altogether if preferred.

In order to simulate atmosphere washout of the virus in precipitation HYSPLIT's existing wet deposition functionality was used. For particle simulations, HYSPLIT requires "In-cloud" and "Below-cloud" deposition constants to be defined through a removal time constant. For the Foot and Mouth Disease virus, in-cloud and below-cloud values of $8 \times 10^{-5}$ are assumed as suggested by the HYSPLIT developers. HYSPLIT incorporates dry deposition if selected by the user. For the FMD virus a dry deposition velocity of $0.01 \mathrm{~m} \mathrm{~s}^{-1}$ is assumed.

Through a combination of new and existing functionality the FMD virus characteristics can now be modelled. These changes have since been incorporated by NOAA and are now standard features in the HYSPLIT model. While the defaults are set to a strain of FMD relevant to Ireland, all of the above mentioned parameters can be adjusted by the user to account for other strains as appropriate (Draxler et al., 2018).

\subsection{Meteorological data}

The HYSPLIT model requires three dimensional gridded meteorology in a specific ARL data format to drive dispersion simulations. To operationalise the FMD resource, two live meteorological streams were developed to provide ARL data formats in real-time. Software infrastructure to generate global ARL data from real-time ECMWF weather forecasts was developed in collaboration with NOAA and ECMWF. 

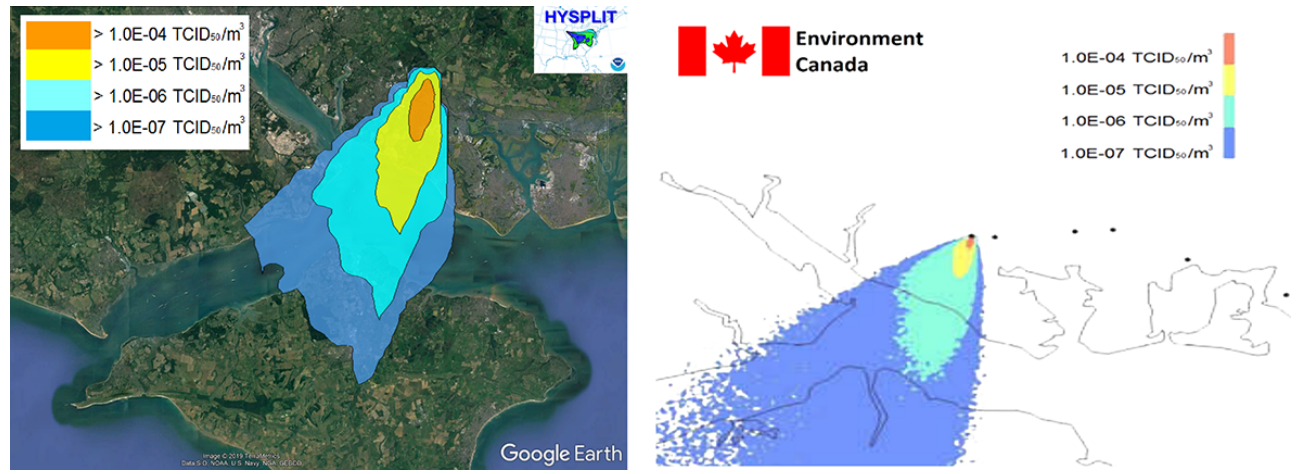

Figure 2. Dispersion plume of FMD from HYSPLIT model for the 1967 Hampshire FMD case study (left). This represents a $24 \mathrm{~h}$ time averaged concentration for the test day of the 9 January 1967 driven by $1^{\circ}$ ECMWF ERA-40 reanalysis meteorological data. This compares well to the same event modelled by the Canadian MLCD dispersion model (right), one of 6 FMD dispersion modelling groups to participate in the FMD intercomparison exercise. The island at the bottom of both images is the Isle of Wight, UK. Concentrations in TCID 50 (50\% Tissue Culture Infective Dose). Left panel background map (c) 2019 Google Earth, ( 2019 TerraMetrics, Data SIO, NOAA. U.S. Navy, NGA, GEBCO, adapted by the authors. Right panel adapted from Gloster et al. (2010), Fig. 4.

These meteorological data derive from the current version of ECMWF's High Resolution Deterministic forecast and are operationally available to the user for the period $10 \mathrm{~d}$ ago to $10 \mathrm{~d}$ ahead, although historic meteorology can be generated on request. It is useful for monitoring outbreaks from overseas, forecasting virus plumes a number of days ahead as well for running backward trajectory analysis to identify potential virus emission sources.

In addition, infrastructure to generate ARL files from Met Éireann's high resolution local area HARMONIE-AROME model (Bengtsson et al., 2017) was also developed. This provides the resolution $(2.5 \mathrm{~km})$ and more accurate modelling of localised convection and terrain, to model the short-range dispersion of the FMD virus from an infected farm. Operationally an archive of the past $35 \mathrm{~d}$ along with a forecast of the next $2 \mathrm{~d}$ is available to the user in real-time. This meteorological product is ideally suited for analysing local outbreak events, nationally.

\subsection{Virus emission model}

The virus emission model (Garner et al., 2006) is designed to populate the atmospheric dispersion model with the estimated concentrations of FMD virus from the source locations. This model is a deterministic state-transition model based on a Markov chain for the different stages of the infection process. The probability of a susceptible animal becoming infected is a function of the number of infected animals in the herd and the effective contact rate (ECR). ECR is defined as the expected number of animals with which one virus-excreting animal will make sufficiently close contact that disease transmission could occur within a given time period. The emission profile will change over time as susceptible animals become infected and start emitting the virus. The species type will also heavily influence the emission profile with pigs being the biggest virus emitter. The model will retrospectively estimate the virus emission profile based on the number of clinically infected animals present at the time of detection. This requires expert opinion from attending veterinary practitioners to estimate when the infection was introduced based on the clinical presentation of infected animals.

\subsection{Farm risk model}

The farm risk or exposure risk model estimates the probability of animals becoming infected based on the plume concentration at ground level and the exposed species type (including multiple species) and stocking densities. There is considerable uncertainty in this model. Coupled with the uncertainty in the emission model and the atmospheric dispersion model which feed into this model, the output is interpreted as relative risk values of high, medium low or very low.

\section{Verification of FMD dispersion functionality}

FMD outbreaks in countries officially FMD-free without vaccination are infrequent. As such there is poor availability of observational data for model validation. However a FMD model intercomparison workshop (Gloster et al., 2010), which took place a number of years before the development of this system, provided the ideal verification reference to test this new FMD functionality within HYSPLIT. In this workshop six separate dispersion models simulated an FMD outbreak in Hampshire, UK in 1969. This case study supports the theory that animals on the island of the Isle of Wight were infected through airborne dispersion of the FMD virus.

A validation simulation of the new HYSPLIT FMD functionality was created to match the emission profile from this workshop. Using the meteorological software infrastructure 
Total $24 \mathrm{~h}$ integrated concentrations along the major axis of the plume 9 Jan 1967 - Hampshire, UK

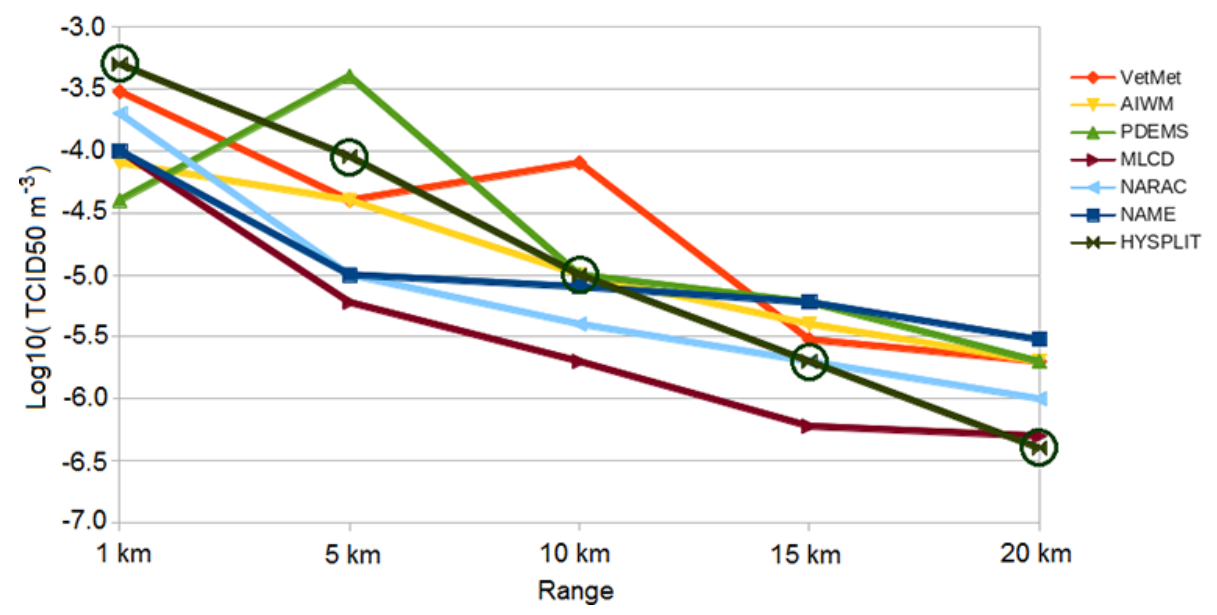

Figure 3. Total integrated concentrations $(24 \mathrm{~h})$ of FMD for 1969 Hampshire case study as a function of distance from emission source (i.e. primary infected farm). The graph shows the results of all 6 models which participated in the 2010 intercomparison [data from Table 3 Gloster et al. 2010], along with the concentrations derived from the new FMD option within HYSPLIT (dark green line with circles). As can be seen all 7 models agree well, with concentrations falling off with distance as expected. The modelling groups include; VetMet, Denmark; AIWM, Australia; PDEMS, New Zealand; MLCD, Canada; NARAC, USA \& NAME, UK. The HYSPLIT line appears near linear because its concentration plume, hence plume axes, is quite uniform leading to a consistent decrease in concentration with distance.

mentioned above, the appropriate ARL formatted meteorological files were created from the ECMWF ERA-40 archive for this period.

The six models from the workshop performed similarly. Figure 2 shows the comparison between one of the models, the Environment Canada model (MLCD) and HYSPLIT. The plume shape and direction appear similar. Figure 3 shows a graphical representation of a table from (Gloster et al., 2010) listing virus concentrations from the infected farm with distance, along the major plume axis, from that farm. The concentrations from the new FMD functionality within HYSPLIT were also added to the six models from the workshop. As can be seen all models agree quite well with virus concentration falling off with distance as expected.

Before NOAA incorporated the new FMD functionality into the HYSPLIT standard release they compared this ECMWF driven simulation of the 1967 case study presented here with their own simulation driven by NCAR meteorological data. The results were similar (Air Resources Laboratory, 2019). It would appear the new FMD functionality, now standard within HYSPLIT, performs comparably to other accepted models at dispersing the FMD virus.

\section{Conclusion}

HYSPLIT now has the ability to model the airborne dispersion of FMD. In Ireland, Met Éireann has developed software infrastructure that automatically generates ARL formatted meteorological data for HYSPLIT as soon as the latest weather forecasts become available. For example this allows virus experts at the Centre for Veterinary Epidemiology and Risk Analysis 24/7 access to run FMD simulations with the latest available forecast information.

Combining this meteorological information with a virus emission model, HYSPLIT can generate virus plumes. When these plumes are combined with a farm risk model utilising GIS farm mapping software, the entire resource becomes a powerful decision support tool. In addition to animal movement restrictions and other contingency plans, the virus wind dispersal resource aids high risk farms being assigned higher priority hence allowing for targeted surveillance. This helps establish a quarantine zone more quickly, helping to reduce the spread of the virus, reducing the number of cullings required, which in turn limits economic losses and protects trading status.

The system also has the added benefit, using existing functionality within HYSPLIT, of identifying potential sources of airborne virus incursions using backward trajectories, which further aids emergency preparedness and eradication strategies.

Data availability. The meteorological data used to drive the HYSPLIT model for the 1969 FMD case study was ECMWF ERA40. This data is available for download from the European Centre for Medium-Range Weather Forecasts meteorological archive (ECMWF, 2019). The setup of HYSPLIT for the case study run is described by Air Resources Laboratory (2019), while the emission profile is provided in Gloster et al. (2010). 
Author contributions. All authors provided critical feedback and helped in the research, development and analysis, including the writing of the manuscript.

Competing interests. The authors declare that they have no conflict of interest.

Special issue statement. This article is part of the special issue "18th EMS Annual Meeting: European Conference for Applied Meteorology and Climatology 2018". It is a result of the EMS Annual Meeting: European Conference for Applied Meteorology and Climatology 2018, Budapest, Hungary, 3-7 September 2018.

Acknowledgements. Authors would like to thank the Bureau of Meteorology, Australia, as well as the Australian Department of Agriculture, Fisheries and Forestry who provided initial guidance on FMD dispersion modeling. Authors would also like to thank Ray McGrath, Met Éireann (retired) for initial guidance and sample meteorological software code.

Review statement. This paper was edited by Josef Eitzinger and reviewed by two anonymous referees.

\section{References}

Air Resources Laboratory: NOAA, Dispersion of Foot and Mouth: available at: https://ready.arl.noaa.gov/documents/TutorialX/ html/emit_fmd.html, last access: 30 May 2019.

Bengtsson, L., Andrae, U., Aspelien, T., Batrak, Y., Calvo, J., De Rooy, W., and Køltzow, M. Ø.: The HARMONIE-AROME model configuration in the ALADIN-HIRLAM NWP system, Mon. Weather Rev., 145, 1919-1935, 2017.

Central Statistics Office: Output, Input and Income in Agriculture Final Estimate, available at: https://www.cso.ie/en/releasesandpublications/er/oiiaf/ outputinputandincomeinagriculture-finalestimate2017/, last access: 2 January 2019.

Draxler, R., Stunde, B. J., Rolph, G. D., Stein, A. F., and Taylor, A.: HYSPLIT User's Guide, NOAA, Maryland, USA, 2018.

ECMWF: ERA-40, available at: https://apps.ecmwf.int/datasets/ data/era40-daily/levtype $=$ sfc/, last access: 17 June 2019.

Garner, M. G., Hess, G. D., and Yang, X.: An integrated modelling approach to assess the risk of wind-borne spread of foot-andmouth disease virus from infected premises, Environ. Model. Assess., 11, 195-207, 2006.

Gloster, J., Jones, A., Redington, A., Burgin, L., Sørensen, J. H., Turner, R., and Paton, D.: Airborne spread of foot-and-mouth disease-model intercomparison, Vet. J., 183, 278-286, 2010.

Knight-Jones, T. J. and Rushton, J.: The economic impacts of foot and mouth disease - What are they, how big are they and where do they occur?, Prev. Vet. Med., 112, 161-173, 2013.
Sørensen, J. H., Jensen, C. Ø., Mikkelsen, T., Mackay, D. J., and Donaldson, A. I.: Modelling the atmospheric dispersion of foot-and-mouth disease virus for emergency preparedness, Phys. Chem. Earth Pt. B, 36, 93-97, 2001.

Stein, A. F., Draxler, R. R., Rolph, G. D., and Stunde, B. J.: NOAA's HYSPLIT Atmospheric Transport and Dispersion Modeling System, B. Am. Meteorol. Soc., 96, 2059-2077, 2015.

World Organisation for Animal Health: FMD official disease status, available at: http://www.oie.int/en/animal-health-in-the-world/ official-disease-status/, last access: 2 January 2019. 